\title{
Produtividade de feijão caupi crioulo em função do espaçamento entre linhas e número de plantas por cova
}

\author{
Felipe Thomaz da Camara ${ }^{1}$, Antônio Marcos Duarte Mota ${ }^{1}$, Francisca Edcarla de Araújo \\ Nicolau $^{2}$, Antônio Alves Pinto ${ }^{1}$, Josefa Maria Franciele da Silva ${ }^{3}$ \\ ${ }^{1}$ Universidade Federal do Cariri, Centro de Ciências Agrárias e da Biodiversidade, Crato, Ceará, Brasil. E-mail: \\ felipe.camara@ufca.edu.br; antonioufca@gmail.com; marquinhosagroproduzir@gmail.com \\ ${ }^{2}$ Universidade Estadual Paulista, Faculdade de Ciências Agrárias e Veterinária, Jaboticabal, São Paulo, Brasil. E-mail: \\ carla_nicolau18@yahoo.com.br \\ ${ }^{3}$ Universidade Federal do Ceará, Campus do Pici, Fortaleza, Ceará, Brasil. E-mail: francielisilva39@ yahoo.com.br
}

Recebido: 22/11/2017; Aceito: 22/03/2018.

\section{RESUMO}

O feijão caupi é uma das principais culturas na região nordeste tendo seu cultivo voltado para a produção de grãos ou em vagens verdes. Desta forma, objetivou-se avaliar o desenvolvimento e a produtividade do feijão caupi em grãos e em vagens verdes em função do espaçamento entre plantas e da prática de desbaste na região do Cariri cearense. O experimento foi conduzido no Sitio Pintado, Missão Velha-CE, delineamento em blocos casualizados, em esquema fatorial $2 \times 3$, com quatro repetições. O primeiro fator foi o espaçamento entre plantas $(0,5 ; 0,33 \mathrm{e}$ $0,25 \mathrm{~m}$ ) e o segundo a prática (ou não) do desbaste Quanto ao desenvolvimento e produtividade do feijão verde, avaliou-se a população de plantas, número de vagens por planta, massa de vagens verdes por planta, massa verde por vagem e produtividade de vagens verdes. Com relação às variáveis de feijão em grãos à $11 \%$ de umidade foi avaliado o número de grãos por vagem, a massa de grãos por planta, a massa de 100 grãos e a produtividade de grãos. A prática do desbaste permitiu maiores valores de produção por planta, porém sem melhoras na produtividade de grãos e vagens verdes. Para o espaçamento entre as plantas, observou-se que as produtividades foram maiores para o espaçamento de 0,4 m entre plantas, com valores de $1633 \mathrm{~kg} \mathrm{ha}^{-1}$ de grãos.

Palavras-chave: Vigna unguiculata (L) Walp, distribuição espacial de plantas, desbaste.

\section{Yield of criollo cowpea beans as a function of row spacing and number of plants per hill}

\begin{abstract}
Cowpea beans are one of the main crops in the Northeast region, and it can be cultivated for grain production or in green pods. This article aimed to evaluate the development and yield of cowpea beans in grains and green pods related of the spacing between plants and the practice of thinning in the Cariri region of Ceará State, Brazil. The trial was run at Sitio Pintado in the municipality of Missão Velha, Ceará, Brazil, in a randomized complete block design in a $2 \times 3$ factorial scheme, with four replications. The first factor was the spacing between plants $(0.50$, 0.33 and $0.25 \mathrm{~m}$ ), and the second was the practice of thinning (with and without thinning). To evaluate the development and yield of green beans, the following variables were analyzed: Plant population, number of pods per plant, the mass of green pods per plant, green mass per pod, and green pods yield. Regarding the variables of bean in grains at $11 \%$ moisture, the number of grains per pod, the grain mass per plant, the mass of 100 grains and the grain yield were evaluated. The thinning practice allowed higher values of production per plant, but without improvements in the yield of green beans and pods. For the spacing between the plants, it was observed that the higher yield of grains was for the spacing of $0.4 \mathrm{~m}$, with values of $1,633 \mathrm{~kg} \mathrm{ha}^{-1}$.
\end{abstract}

Key words: grains, green pods, plant spacing, thinning. 


\section{Introdução}

O feijão-caupi [Vigna unguiculata (L.) Walp.] apresenta vários nomes comuns no Brasil, tais como: feijão-da-estrada, feijão-de-praia, feijão-de-rama, feijãofradinho ou feijão macassar, feijão-de-corda, macáçar ou macaça. Apresenta importante papel na dieta alimentar, sendo uma das principais fontes de proteínas das famílias, principalmente das regiões Norte e Nordeste do Brasil, sendo consumido na forma de grãos verdes ou secos (NEVES et al., 2011).

Para a região Nordeste é considerada uma planta adaptada às condições edafoclimáticas em virtude de possuir tolerância a altas temperaturas, a períodos de estiagem (veranicos) e apresentar ciclo curto. Segundo Oliveira et al. (2002), é amplamente cultivada nas áreas irrigadas do Nordeste. É considerada uma cultura com grande importância socioeconômica por fixar a mão-deobra no campo (BASTOS et al., 2012).

Em função da sua adaptabilidade a diversas regiões e alta demanda mundial, observa-se aumento na produção mundial em $35,1 \%$ no período compreendido entre 1975 e 2005 . Nesse período o Brasil passou a ser o maior produtor mundial, seguido por Índia e China. (WANDER, 2007).

Conforme o IBGE (2017), atualmente o Brasil ocupa a terceira posição na produção mundial de feijão, com uma área cultivada em torno 3,1mil hectares, com produção média de $1.083 \mathrm{~kg} \mathrm{ha}^{-1}$. Para se elevar a produtividade da cultura é essencial que se observe a densidade das plantas e o arranjo entre as plantas de feijão a fim de se obter a melhor combinação dos espaçamentos entre plantas e fileiras. (BEZERRA et al., 2009). Desta forma, o espaçamento entre fileiras e a densidade populacional determinam o nível de competição entre as plantas; esta combinação tem influência direta no aproveitamento da luz, água e nutrientes.

Conforme Bezzera et al. (2012), alterações na população de plantas proporcionam diferenças significativas na morfologia da planta, com reduções do diâmetro do caule e do número de ramos laterais, bem como nos componentes de produção, com reduções no número de vagens por planta, na produção de grãos por planta e rendimento de grãos.

Este arranjo de plantas ideal para a cultura é muito afetado na região nordeste em função da semeadura realizada com matraca, depositando de duas a cinco sementes por cova, sendo comum a regulagem com três sementes por cova, sem a prática de desbaste posteriormente. Desta forma, o objetivo do artigo foi avaliar o desenvolvimento e a produtividade do feijão caupi em grãos e em vagens verdes em função do espaçamento entre as plantas e da prática de desbaste na região do Cariri cearense, em sistema de cultivo irrigado por aspersão.

\section{Material e Métodos}

O experimento foi conduzido no período de agosto a outubro de 2012 no Sitio Pintado no município de Missão Velha-Ceará, localização geodésica definida pelas coordenadas $07^{\circ} 14^{\prime} \mathrm{S}$ e $39^{\circ} 08^{\prime} \mathrm{W}$, com altitude média de $380 \mathrm{~m}$. Segundo o IPECE (2011), a região apresenta temperatura média anual de $25^{\circ} \mathrm{C}$, precipitação média anual de $987 \mathrm{~mm}$; o clima da região é definido como Aw segundo a classificação de Köeppen. O solo classificado como Argissolo Amarelo de textura franco-arenosa.

$\mathrm{O}$ experimento foi conduzido em delineamento, blocos casualizados em esquema fatorial $2 \times 3$, com quatro repetições. $\mathrm{O}$ primeiro fator foi o espaçamento entre plantas $(0,50 ; 0,33$ e $0,25 \mathrm{~m})$; o segundo fator foi a prática (ou não) do desbaste. A área útil das parcelas de $25 \mathrm{~m}^{2}$ foi composta por cinco fileiras com espaçamento de $0,50 \mathrm{~m}$ e $10 \mathrm{~m}$ de comprimento dos quais três metros foram separados para se avaliar a produção em grãos e outros três metros em vagens verdes. Portanto, a área útil para análise compreendeu 3 fileiras centrais com três metros de comprimento $\left(4,50 \mathrm{~m}^{2}\right)$.

O preparo do solo foi realizado por meio de gradagem leve, utilizando-se um trator com tração $4 \times 2$ da marca Ford, modelo 5610 , potência de $62,56 \mathrm{~kW}$ ( 85 cv) e uma grade leve em tandem com 12 discos recortados e largura de $1,5 \mathrm{~m}$. Utilizou-se, como há vários anos pelos agricultores do Sítio Pintado, feijão caupi variedade crioula da subclasse manteiga, de acordo com a classificação de Freire-Filho et al. (2005). A planta apresenta como característica principal o crescimento determinado, com ciclo de 60 dias e porte ereto. Os melhores grãos do cultivo anterior usualmente selecionados e separados servem de semente para o próximo cultivo.

A semeadura do feijão-caupi foi realizada manualmente, depositadas três sementes por cova, com espaçamento de $0,5 \mathrm{~m}$ entre as fileiras. Para os tratamentos com desbaste o mesmo foi realizado aos 17 dias após a semeadura (DAS) deixando no campo apenas uma planta por cova. A Tabela 1 mostra o número de sementes utilizadas na semeadura do feijão caupi para cada tratamento.

Em todas as parcelas foi necessária a aplicação de inseticida Lorsban $480 \mathrm{BR}$, para controle do pulgão e mosca branca, principais pragas da cultura. Para controle das plantas daninhas foram efetuadas duas capinas manuais.

Durante a condução da cultura do feijão caupi não ocorreram precipitações atmosféricas, portanto, a cultura foi irrigada por 2 horas a cada dois dias por aspersão, por um período de 60 dias após a semeadura (DAS), conforme a Figura 1, totalizando $300 \mathrm{~mm}$ durante o ciclo da cultura. 
Tabela 1. Número de sementes utilizadas na semeadura do feijão-caupi para os arranjos populacionais estudados

\begin{tabular}{ccc}
\hline $\begin{array}{c}\text { Fator 1 } \\
\text { (Espaçamento entre plantas) }\end{array}$ & $\begin{array}{c}\text { Fator 2 } \\
\text { (Desbaste) }\end{array}$ & Sementes ha $^{-1}$ \\
\hline \multirow{2}{*}{$0,25 \mathrm{~m}$} & Com & 80.000 \\
& Sem & 240.000 \\
\multirow{2}{*}{$0,33 \mathrm{~m}$} & Com & 60.000 \\
& Sem & 180.000 \\
\multirow{2}{*}{$0,50 \mathrm{~m}$} & Com & 40.000 \\
& Sem & 120.000 \\
\hline
\end{tabular}

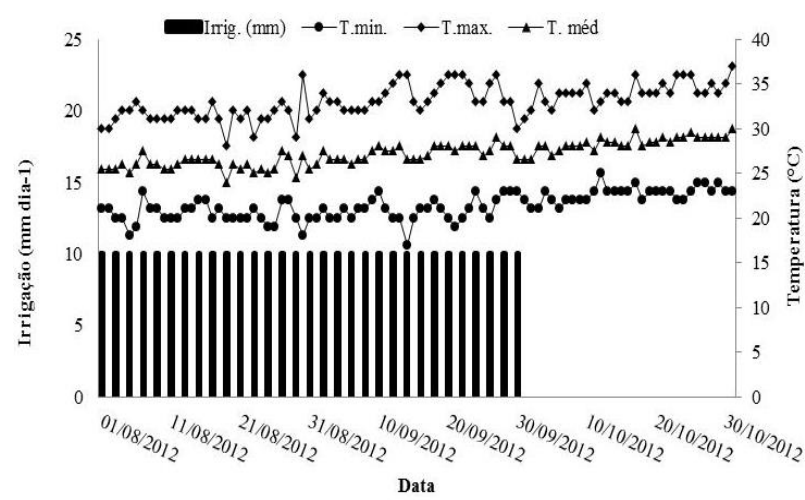

Figura 1. Dados de irrigação (Irrig.), temperatura mínima (T. min.), temperatura máxima (T.max.) e temperatura média ( $\mathrm{T}$. méd) durante o ciclo da cultura.

Aos 60 DAS iniciou-se a colheita do feijão caupi verde manualmente; em função da maturação desuniforme das vagens realizaram-se três colheitas de feijão verde, a cada 5 dias, visando evitar maiores perdas obtendo melhor qualidade do produto. Para a análise do feijão seco a colheita foi realizada em apenas uma etapa, aos 90 DAS quando as vagens estavam secas.

Para se avaliar o desenvolvimento e produtividade do feijão verde, foram analisadas as seguintes variáveis: População de plantas, o número de grãos por vagem, número de vagens por planta, massa de vagens verdes por planta, massa verde por vagem e produtividade de vagens verdes. A população de plantas foi avaliada contando-se todas as plantas contidas na área útil, com os dados sendo extrapolados para número de plantas por hectare. Para o número de grãos por vagem foi realizada a contagem do número de grãos de 25 vagens por ponto amostral, escolhidas ao acaso. O número de vagens por planta foi obtido através da relação entre o número de vagens pelo número de plantas colhidas na área útil.

A massa de vagens verdes por planta foi obtida pela relação entre a massa de todas as vagens e o número total de plantas contidas na área útil. Em relação à massa verde por vagem, todas as vagens colhidas na parcela útil foram pesadas e divididas pelo número total de vagens. A produtividade de vagens verdes foi calculada em função da massa total de vagens colhidas na parcela útil e extrapolada para quilogramas por hectare.
Com relação às variáveis de feijão em grãos a $11 \%$ de umidade foram avaliados a massa de grãos por planta, a massa de 100 grãos e a produtividade de grãos. A massa de grãos por planta foi calculada pela razão entre a massa de grãos e o número de plantas coletadas na área útil. Para a massa de 100 grãos foi efetuada a relação entre a produtividade de grãos e a população de plantas, e o resultado extrapolado para massa de 100 grãos. A produtividade foi determinada através da pesagem em balança de precisão semi-analítica de todos os grãos contidos na área útil. Os valores foram extrapolados para quilogramas por hectare.

Para comparar e interpretar os resultados, os dados foram submetidos à análise de variância pelo teste $\mathrm{Fe}$ as médias do fator desbaste foram comparadas pelo teste de Tukey a $5 \%$ de probabilidade; os dados referentes ao espaçamento entre plantas foram submetidos à análise de regressão para seleção do modelo com maior expoente significativo. As análises foram realizadas no programa estatístico Sisvar (FERREIRA, 2011).

\section{Resultados e Discussão}

Os resultados da análise de variância não reportaram interação significativa entre os fatores para todas as variáveis estudadas (Tabela 2), sendo possível avaliar os fatores separadamente por meio da média. Verifica-se que para a população final de plantas houve diferença significativa $(\mathrm{p}<0,01)$ para $o$ fator desbaste, nas parcelas onde não foi realizado o desbaste a população foi superior, evidenciando que a cultura do feijão, mesmo em alta densidade populacional, apresenta baixo índice de mortalidade de plantas. Das sementes depositadas nos tratamentos com e sem desbaste chegaram à fase reprodutiva $78,7 \%$ e $74,0 \%$, respectivamente (Tabela 1 ).

Tal fato também foi observado em relação ao espaçamento entre as plantas (Tabela 1), havendo aumento no número de plantas na medida em que se reduziu o espaçamento entre as plantas de 0,50 para $0,25 \mathrm{~m}$. Na Tabela 2, nota-se que para o número de grãos por vagem e a massa verde por vagem não ocorreu diferença significativa para o desbaste de plantas e o espaçamento. Resultados semelhantes foram reportados por Cardoso e Ribeiro (2006), os quais observaram que o aumento no número de plantas por área não eleva significativamente a massa de grãos de feijão por vagem.

Brito et al. (2015) avaliando cinco genótipos de feijão-caupi em Campina Grande-PB, obtiveram de 11 a 14 grãos de feijão-caupi por vagem, porém sem diferença entre os genótipos avaliados. Tais valores foram inferiores aos deste trabalho que obteve média próxima a 15 grãos por vagem. 
Tabela 2. Síntese da análise de variância e do teste de médias para a população final (População), o número de grãos por vagem $(\mathrm{NG} / \mathrm{V})$, o número de vagens por planta $(\mathrm{NV} / \mathrm{P})$, a massa de vagens verdes por planta $(\mathrm{MVV} / \mathrm{P})$, a massa verde por vagem $(\mathrm{MV} / \mathrm{V})$.

\begin{tabular}{|c|c|c|c|c|c|}
\hline \multirow{2}{*}{ Fontes de Variação } & \multicolumn{5}{|c|}{ Quadrados Médios } \\
\hline & População & $\mathrm{NG} / \mathrm{V}$ & $\mathrm{NV} / \mathrm{P}$ & MVV/P & $\mathrm{MV} / \mathrm{V}$ \\
\hline Desbaste (D) & $112,67 * *$ & $0,42^{\mathrm{NS}}$ & $37,92 * *$ & $16,68 * *$ & $2,77^{\mathrm{NS}}$ \\
\hline Espaçamento (E) & $6,52 *$ & $1,54^{\mathrm{NS}}$ & $11,39 * *$ & $3,10 *$ & $0,05^{\mathrm{NS}}$ \\
\hline $\mathrm{D} * \mathrm{E}$ & $1,01^{\mathrm{NS}}$ & $3,88^{\mathrm{NS}}$ & $2,21^{\mathrm{NS}}$ & $0,36^{\mathrm{NS}}$ & $1,19^{\mathrm{NS}}$ \\
\hline $\mathrm{CV} \%$ & 19,04 & 6,11 & 27,16 & 48,79 & 26,94 \\
\hline \multirow{2}{*}{ Teste de Médias } & População & NG/V & $\mathrm{NV/P}$ & MVV/P & $\mathrm{MV} / \mathrm{V}$ \\
\hline & Plantas ha ${ }^{-1}$ & Unidade & Unidade & g & G \\
\hline \multicolumn{6}{|l|}{ Desbaste } \\
\hline Com & $47.243 \mathrm{~b}$ & $14,67 \mathrm{a}$ & $7,49 \mathrm{a}$ & 55,44 a & $7,56 \mathrm{a}$ \\
\hline Sem & $133.169 \mathrm{a}$ & $14,94 \mathrm{a}$ & $3,25 \mathrm{~b}$ & $20,00 \mathrm{~b}$ & $6,11 \mathrm{a}$ \\
\hline \multicolumn{6}{|l|}{ Espaçamento (m) } \\
\hline 0,25 & $105.185 \mathrm{a}$ & $15,33 \mathrm{a}$ & $3,10 \mathrm{~b}$ & $22,8 \mathrm{~b}$ & $7,0 \mathrm{a}$ \\
\hline 0,33 & $95.062 \mathrm{ab}$ & $14,50 \mathrm{a}$ & $6,10 \mathrm{a}$ & $42,2 \mathrm{ab}$ & $6,7 \mathrm{a}$ \\
\hline 0,50 & $70.370 \mathrm{~b}$ & $14,58 \mathrm{a}$ & $6,92 \mathrm{a}$ & $48,2 \mathrm{a}$ & $6,8 \mathrm{a}$ \\
\hline
\end{tabular}

Médias seguidas pela mesma letra minúscula na coluna, não diferem entre si pelo teste de Tukey a 5\% de probabilidade. **: significativo (P<0,01); *: significativo ( $\mathrm{P}<0,05)$; NS: não significativo; $\mathrm{CV} \%$ : coeficiente de variação.

Para o número de vagens por planta, o desbaste apresentou resultados significativos, apresentando valor superior ao tratamento sem desbaste (Tabela 2). Em relação ao espaçamento entre as plantas, observa-se que o adensamento das plantas proporcionou redução do $\mathrm{NV} / \mathrm{P}$.

O aumento da competição suscitado nas populações mais adensadas teve efeito direto na capacidade produtiva da planta. Vários autores afirmam que o número de vagens por planta é o componente de produção mais afetado pelo aumento na densidade de plantas (CARDOSO; RIBEIRO, 2006; BEZERRA et al., 2008; BEZERRA et al., 2012; OLIVEIRA et al., 2015). Bezerra et al. (2009) trabalhando com o feijão caupi, verificaram que a população de plantas apresenta efeito significativo sobre o número de vagens por plantas (NVP) e que o aumento da densidade populacional de 100 mil para 300 mil plantas ha $^{-1}$ reduziu o NVP em $63 \%$. Neste experimento a diferença foi ainda maior, chegando a ser $130 \%$ superior para o tratamento com desbaste (47.243 $\left.\mathrm{pl} \mathrm{ha}^{-1}\right)$ em relação ao sem desbaste (133.169 $\left.\mathrm{pl} \mathrm{ha}^{-1}\right)$.

Verifica-se que, com relação à massa de vagens verdes por planta, houve diferença estatística para o desbaste, obtendo melhor resultado com o uso desta prática e evidenciando desta forma a importância do desbaste para se obter grãos maiores e de boa qualidade (Tabela 1). Quanto ao espaçamento entre as plantas, o aumento de 0,25 para $0,50 \mathrm{~m}$ provocou aumento da MVV/P.
Conforme Tabela 3, nota-se que não houve interação significativa entre os fatores para todas as variáveis estudadas. A variável massa de grãos por planta apresentou diferença significativa $(\mathrm{p}<0,01)$ para $\mathrm{o}$ desbaste, proporcionando aumento de $122,7 \%$ na massa de grãos por planta. A redução do espaçamento entre plantas proporcionou menores valores para a massa de grãos por planta. Desta forma, nota-se que os tratamentos que apresentaram maior número de plantas obtiveram resultados inferiores, onde a competição intraespecífica foi o motivo principal da redução na massa de grãos secos por planta, em virtude da diminuição no vingamento de flores. Resultado este também observado por Távora et al. (2001).

Para a massa de cem grãos (Tabela 3), observa-se que o desbaste e o espaçamento não obtiveram resultados significativos. Com relação à variável produtividade de grãos e massa de vagens verdes, notase que não houve diferença significativa para a prática de desbaste; apesar dos benefícios de melhoria na produção por planta, a produtividade foi similar aos tratamentos em que não foi realizada esta prática (Tabela 3).

Para o espaçamento entre as plantas observa-se maior produtividade de grãos e de vagens verdes para o espaçamento de $0,33 \mathrm{~m}$ entre plantas, alcançando maiores produtividades com valor de espaçamento intermediário, fato que contradiz a pesquisa de Cardoso e Ribeiro (2006) demonstrando que a diminuição na densidade populacional provoca quedas significativas na produção de grãos. 
Tabela 3. Síntese da análise de variância e do teste de médias para a massa de grãos secos por planta (MG/P), a massa de cem grãos secos (M100G), produtividade de grãos secos (PG) e a produtividade de vagens verdes (PVV).

\begin{tabular}{|c|c|c|c|c|}
\hline \multirow{2}{*}{ Fontes de Variação } & \multicolumn{4}{|c|}{ Quadrados Médios } \\
\hline & MG/P & M100G & PG & PVV \\
\hline Desbaste (D) & $23,66 * *$ & $2,31^{\mathrm{NS}}$ & $1,64^{\mathrm{NS}}$ & $0,01^{\mathrm{NS}}$ \\
\hline Espaçamento (E) & $6,37 *$ & $2,97^{\mathrm{NS}}$ & $3,08 *$ & $2,91 *$ \\
\hline $\mathrm{D} * \mathrm{E}$ & $1,37^{\mathrm{NS}}$ & $1,43^{\mathrm{NS}}$ & $0,32^{\mathrm{NS}}$ & $0,29^{\mathrm{NS}}$ \\
\hline $\mathrm{CV} \%$ & 33,16 & 2,33 & 36,58 & 42,12 \\
\hline \multirow{2}{*}{ Teste de Médias } & MG/P & M100G & PG & PVV \\
\hline & G & G & $\mathrm{kg} \mathrm{ha}^{-1}$ & $\mathrm{~kg} \mathrm{ha}^{-1}$ \\
\hline \multicolumn{5}{|l|}{ Desbaste } \\
\hline Com & $23,12 \mathrm{a}$ & $21,3 \mathrm{a}$ & $1.049 \mathrm{a}$ & $2.504 \mathrm{a}$ \\
\hline Sem & $10,38 \mathrm{~b}$ & $21,2 \mathrm{a}$ & $1.309 \mathrm{a}$ & $2.456 \mathrm{a}$ \\
\hline \multicolumn{5}{|l|}{ Espaçamento (m) } \\
\hline 0,25 & $10,19 \mathrm{~b}$ & $21,4 \mathrm{a}$ & $874 \mathrm{~b}$ & $1.707 \mathrm{~b}$ \\
\hline 0,33 & $19,38 \mathrm{a}$ & $21,4 \mathrm{a}$ & $1.492 \mathrm{a}$ & $3.151 \mathrm{a}$ \\
\hline 0,50 & $20,70 \mathrm{a}$ & $20,8 \mathrm{a}$ & $1.172 \mathrm{ab}$ & $2580 \mathrm{ab}$ \\
\hline
\end{tabular}

Médias seguidas pela mesma letra minúscula na coluna, não diferem entre si pelo teste de Tukey a 5\% de probabilidade. **: significativo (P<0,01); *: significativo ( $\mathrm{P}<0,05)$; NS: não significativo; CV\%: coeficiente de variação.

A produtividade de grãos secos foi semelhante à obtida por Bezerra et al. (2012), variando de 750 a 1700 $\mathrm{kg} \mathrm{ha}^{-1}$, enquanto que Silva et al. (2013) avaliando oito cultivares de feijão caupi obtiveram média de $2138 \mathrm{~kg}$ $\mathrm{ha}^{-1}$ de vagens verdes; valor inferior à máxima produtividade observada neste artigo, comprovando que o material crioulo avaliado apresenta-se como boa alternativa para a região.

\section{Conclusões}

O espaçamento entre plantas de $0,33 \mathrm{~m}$ proporciona melhor desempenho na produtividade de feijão-caupi em grãos secos e em vagens verdes.

A prática do desbaste melhora a produção individual por planta sem proporcionar ganhos significativos em produtividade.

\section{Referências Bibliográficas}

BASTOS, E. A.; RAMOS, H. M. M.; ANDRADE JÚNIOR, A. S.; NASCIMENTO, F. N.; CARDOSO, M. J. Parâmetros fisiológicos e produtividade de grãos verdes do feijão-caupi sob déficit hídrico. Water Resources and Irrigation Management, Cruz das Almas-BA, v. 1, n. 1, p.31-37, 2012.

BEZERRA, A. A. C.; ALCÂNTARA NETO, F.; NEVES, A. C.; MAGGIONI, K. Comportamento morfoagronômico de feijão-caupi, cv. BRS Guariba, sob diferentes densidades de plantas. Revista Ciências Agrárias, Belém-PA, v. 55, n. 3, p. 184-189, 2012.
BEZERRA, A. A. C.; TÁVORA, F. J. A. F.; FREIRE FILHO, F. R.; RIBEIRO, V. Q. Características de dossel e de rendimento em feijão-caupi ereto em diferentes densidades populacionais. Pesquisa Agropecuária Brasileira, BrasíliaDF, v. 44, n. 10, p. 1239-245, 2009.

BEZERRA, A. A. C.; TÁVORA, F. J. A. F.; FREIRE FILHO, F. R. Morfologia e produção de grãos em linhagens modernas de feijão-caupi submetidas a diferentes densidades populacionais. Revista de Biologia e Ciências da Terra, Campina Grande-PB, v. 8, n. 1, p. 1-9, 2008.

BRITO, K. Q. B.; NASCIMENTO, R.; SANTOS, J. E. A.; SILVA, I. A. C.; DANTAS JUNIOR, G. J. Componentes de produção de genótipos de feijão-caupi irrigados com água salina. Revista Verde, Pombal-PB, v. 10, n. 4, p. 01-05, 2015.

CARDOSO, M. J.; RIBEIRO, V. Q. Desempenho agronômico do feijão-caupi, cv. Rouxinol, em função de espaçamentos entre linhas e densidades de plantas sob regime de sequeiro. Revista Ciência Agronômica, Fortaleza-CE, v. 37, n. 01, p. 102-105, 2006.

FERREIRA, D. F. Sisvar: a computer statistical analysis system. Ciência e Agrotecnologia, Lavras-MG, v. 35, n. 6, p. 1039-1042, 2011.

FREIRE FILHO, F. R.; LIMA, J. A. A.; RIBEIRO, V. Q. (Ed.). Feijão-caupi: avanços tecnológicos. Brasília-DF: Embrapa Informação Tecnológica, 2005. 519 p.

IBGE. INSTITUTO BRASILEIRO DE GEOGRAFIA E ESTATÍSTICA. Estatística da Produção Agrícola Setembro de 2017. Disponível em: https://ww2.ibge.gov.br/home/estatistica/indicadores/agropecu aria/lspa/1spa_201709_6.shtm.Acesso em: 17 nov. 2016. 
IPECE. INSTITUTO DE PESQUISA E ESTRATÉGIA ECONÔMICA DO CEARÁ. Perfil básico municipal 2011, Missão Velha-CE: IPECE, 2011. 18 p.

NEVES, A. C.; CÂMARA, J. A. S.; CARDOSO, M. J.; SILVA, P. H. S.; SOBRINHO, C. A. Cultivo do feijão-caupi em sistema agrícola familiar. Teresina- PI: Embrapa Meio norte, 2011. , p. 15 (Circular Técnica, 51)

OLIVEIRA, A. P.; TAVARES SOBRINHO, J.; NASCIMENTO, J. T; ALVES, A. U; ALBUQUERQUE, I. C.; BRUNO, G. B. Avaliação de linhagens e cultivares de feijão-caupi, em Areia, PB. Horticultura Brasileira, BrasíliaDF, v. 20, n. 2, p. 180-182, 2002.

OLIVEIRA, S. E. M.; ANDRADE JÚNIOR, A. S.; RIBEIRO, V. Q.; BRITO, R. R.; CARVALHO, M. W. Interação de níveis de água e densidade de plantas no crescimento e produtividade do feijão-caupi, em Teresina, PI. Irriga, Botucatu-SP, v. 20, n. 3, p. 502-513, 2015.
SILVA, E. B.; BARROS JÚNIOR, A. P.; SILVEIRA, L. M.; SANTANA, F. M. S.; SANTOS, M. G. Avaliação de cultivares de feijão-caupi irrigado para produção de grãos verdes em Serra Talhada - PE. Revista Caatinga, MossoróRN, v. 26, n. 1, p. 21-26, 2013.

TÁVORA, F. J. A. F.; NOGUEIRA, S. L.; PINHO, J. L. N. Arranjo e população de plantas em cultivares de feijão-decorda com diferentes características de copa. Ciência Agronômica, Fortaleza,-CE, v. 32, n. 1/2, p. 69-77, 2001.

WANDER, A. E. Produção e consumo de feijão no Brasil, 1975-2005. Informações Econômicas, São Paulo-SP, v. 37, n. 2, p. 07-21, 2007. 